\title{
POSSIBILITIES AND METHODS OF IN-FLIGHT LOADING MEASUREMENT
}

\author{
Ivo Jebáček, Marek Horak \\ Brno University of Technology, Institute of Aerospace Engineering, Technicka 2896/2, 61669 Brno, \\ Czech Republic \\ E-mail: jebacek@fme.vutbr.cz (corresponding author)
}

Received 23 March 2012; accepted 11 May 2012

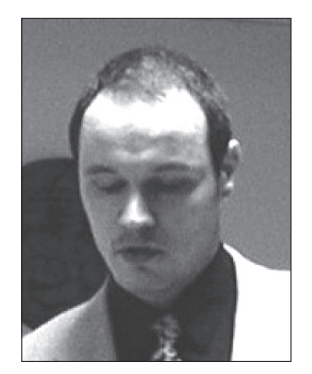

Ivo JEBÁČEK, Assoc. Prof, PhD Eng.

Education: 2009 - associate professor, University of Technology, Faculty of

Mechanical Engineering, specialisation: design and process engineering; 2002 -

PhD, Brno University of Technology, Faculty of Mechanical Engineering,

specialisation: design and process engineering - postgraduate course; 1991-

1996 - Brno University of Technology, Faculty of Mechanical Engineering,

specialisation: aeronautical engineering.

Affiliations and functions: 2006 - head of Aircraft Testing Laboratory

at Institute of Aerospace Engineering; 2002 - senior lecturer, Institute of

Aerospace Engineering FME BUT; 1999-2002 - assistant, Institute of

Aerospace Engineering FME BUT; 1998-1999 - technical worker, Institute of

Aerospace Engineering FME BUT.

Research interests: in-flight testing, laboratory testing of aircraft structures, measurement of mechanical values.

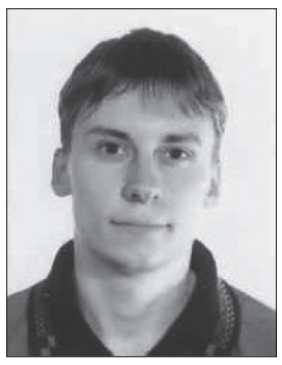

\section{Marek HORAK}

Education: Brno University of Technology.

Affiliation and functions: post-graduate student at Brno University of Technology since 2009.

Research interests: aircraft design, stress analysis of aircraft structures.

Abstract. This article provides information about in-flight measurement of a small sport aircraft. First strain gauges were installed in the wing structure and then calibration procedures were done. After the calculation of strain gauge coefficients, equations for calculating bending moments and other variables were established.

A data acquisition system was installed in the aircraft to measure responses from strain gauges and other variables such as speed, altitude, load factor, and temperature. Many flights were performed with the aircraft equipped this way, and after that the recorded data were analysed and those results were compared with the calculations and static strength tests performed before.

Keywords: measurement, in-flight, strain gauges, fatigue, bending moment, strength test. 


\section{Introduction}

In-flight testing is one of the very important processes of aircraft development. The results of measurement are valuable date for aircraft certification, and they can help further aircraft development as well.

To consider the possibilities of flight loading measurements as global characteristics in a cross section of a given structure, there are two basic principles (Jebáček 2005):

1) measurements of pressure distribution,

2) measurements of strain distribution.

The main disadvantage of measurements of pressure distribution is the necessity to know how pressure spreads along the structure, which requires a considerable amount of measurement points and some changes in the structure itself. Furthermore, another loading calculation from measured pressure distribution is required. If strain gauges are used, it is possible to achieve good results with a small amount of measurement points, and the measurement equipment can be set so individual loading components can be scanned directly during flight.

\section{Calibration method}

The basic issue of measuring with strain gauges is to locate them properly on the structure. Generally there are six components of loading that affect the structural member of the aircraft: $\mathrm{T}_{\mathrm{X}}, \mathrm{T}_{\mathrm{Y}}, \mathrm{T}_{\mathrm{Z}}, \mathrm{M}_{\mathrm{X}}, \mathrm{M}_{\mathrm{Y}}$ and $\mathrm{M}_{\mathrm{Z}}$ ] (Gudkov, Lesakov 1972).

To determine them by means of strain gauge methods, we have to introduce the following presumptions:

- with various loadings of the structure being examined, the deformation-loading relation must be linear;

- the deformation of the part of the structure with the action of all components of loading equals the sum of deformations developed from separate loading components.

For non-linear deformation-loading relations, we have to select different methods of calibration. Then we can simplify that the electric output of .... ${ }^{\text {th }}$ bridge $m_{i}$ $(\% \Delta R / R)$ is expressed by this relation.

$$
m_{i}=b_{i 1} \cdot T+b_{i 2} \cdot M_{o}+b_{i 3} \cdot M_{K},
$$

where:

$\begin{array}{ll}T[\mathrm{~N}] & \text { shear force } \\ M_{o}[\mathrm{Nm}] & \text { bending moment } \\ M_{K}[\mathrm{Nm}] & \text { torque moment } \\ M_{o}=\text { T.z }[\mathrm{Nm}] & \mathrm{z} \text { are shear force arm } \\ M_{K}=\text { T.x }[\mathrm{Nm}] & \mathrm{x} \text { are shear force arm }\end{array}$

Then we can deduce that the relationship between response $\boldsymbol{m}$ of the strain gauge and the overall loading of the structure is revealed by equation (Skopinski, Aiken 1953):

$$
\left\|\begin{array}{c}
T \\
M_{o} \\
M_{K}
\end{array}\right\|=\left\|\begin{array}{cccc}
b_{11} & b_{12} & \ldots & b_{1 j} \\
b_{21} & b_{22} & \ldots & b_{2 j} \\
b_{31} & b_{32} & \ldots & b_{3 j}
\end{array}\right\| *\left\|\begin{array}{c}
m_{1} \\
m_{2} \\
\ldots . . \\
m_{j}
\end{array}\right\| .
$$

And now it is possible to determine an equation for calculating coefficients $\boldsymbol{b}$ :

$$
\left\|b_{i j}\right\|=\|\| m_{n j}\left\|^{T} *\right\| m_{n j}\|\|^{-1} *\left\|m_{n j}\right\|^{T} *\left\|T_{n}^{\prime}\right\| \| .
$$

These equations were used to calculate calibration coefficients of strain gauges installed in a wing of a small sports aircraft. The measuring objective was primarily to define bending moments depending on the flight mode and to compare them with calculations of loading.

Strain gauges were installed first in defined positions, and the calibration of the whole construction according to the aforementioned equations followed. A schema with the strain gauges as typically installed in cut 1 is on Figure 1. We used this strain gauge placement in four cuts. The strain gauges are installed in a real structure on Figure 2. Strain gauges for measurement of the torque moment were also installed on the wing skin, but the skin of this type of aircraft is too thin and loses stability very easily. For that reason, equation (3) is not valid.

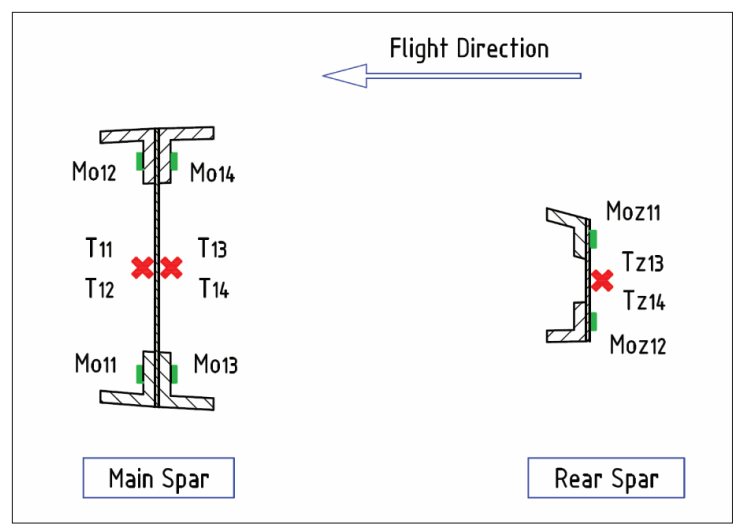

Fig. 1. Installation schema of cut 1

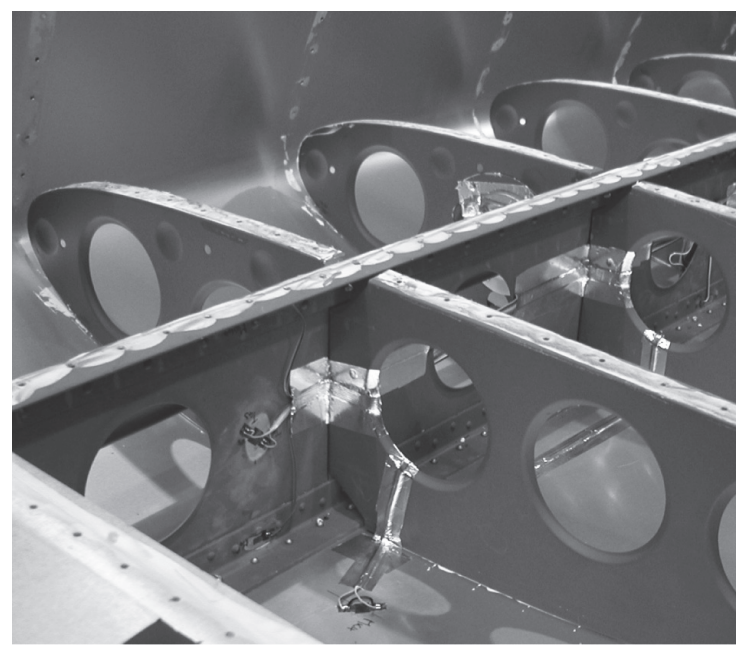

Fig. 2. Strain gauges installed in the structure 


\section{Equipment and measured values}

During in-flight testing, these values were measured:

- responses from the strain gauges installed,

- load factor at centre of gravity,

- forward and backward acceleration,

- static pressure,

- overall pressure.

There was a total of 36 strain gauges installed (of which 12 were rosettes) in 4 cuts along the wingspan.

Indicated air speed VIAS was calculated by this equation:

$$
V_{I A S}=\sqrt{\frac{2 \Delta p}{\rho}}
$$

and pressure altitude:

$$
h=\frac{\sqrt[5,256]{\frac{p}{p_{0}}}-1}{\frac{-0,0065}{T_{0}}}
$$

where $p$ is measured pressure, $\rho$ is air density, and $p_{0}$ and $\mathrm{T}_{0}$ are pressure and temperature at middle sea level.

An ESAM CF data acquisition system was used for recording all needed values. This data acquisition system can record with sampling frequency up to one hundred thousand samples per second. But for these quasi-static measurements, we used 100 samples per second. The measurement unit has own internal memory card, and we did not need any computer during the measurement.

\section{In-flight measurement}

After the aircraft was fully ready to fly (installing measurement system, weighing, defining the centre of gravity of the airplane), measurement flights were done. A total of 16 flights were performed and the total time was near 8 hours. Each flight was defined exactly to get the needed values.

Measurement was divided into two parts. The first part was focused on the measurement of bending moments and second part was focused on the measurement of strain in the defined places. This required small changes in the installation of strain gauges.

The aircraft prepared for measurement is shown in Figure 3.

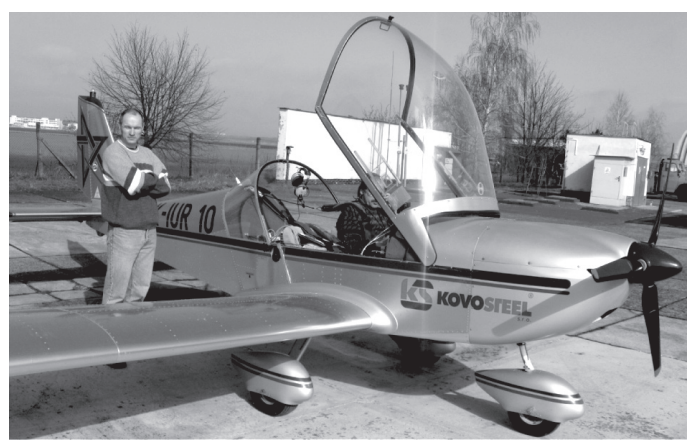

Fig. 3. Aircraft prepared for measurement

\section{Measured and calculated values}

\subsection{Measurement of the bending moment}

After flight, the bending moment curves were defined for various flight modes. Calibration coefficients from equation (3) were used for this calculation.

The values of bending moments were calculated for corresponding measured speed and load factors. The procedure of calculation was similar to calculating loads for static strength tests. Comparisons of calculated and measured values of the bending moments are in Figure 5. There are measured bending moments for load factors 1 , 2, 3, 4 and 6. Calculated values correspond with bending moments at load factor $\mathrm{n}=4$ at the same flight configurations. This graph evidently shows that the measured bending moment is about twelve per cent higher. Similar analyses were done for other significant flight cases.

The measured data was recorded from the internal memory of the ESAM CF data acquisition system. Some data, where the needed values were correct, was taken from each flight performed, and some mean values (Fig. 4) were calculated from this data.

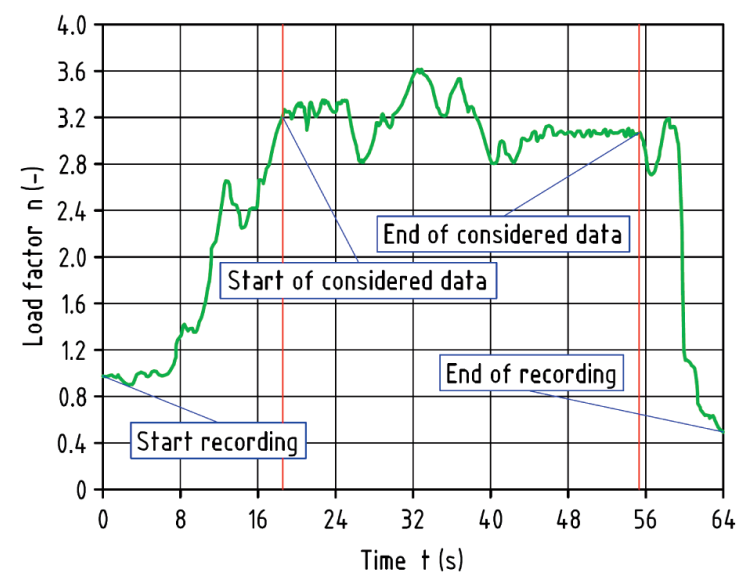

Fig. 4. Fundamentals of chosen measured data

\subsection{Measurement of strain during flight and static strength test}

After in-flight testing, we had the possibility to perform a static strength test of the same wing of this aircraft. The strain gauges were placed on the same position as they were for in-flight testing (Fig. 1). After the testing, the strains from each cut and each strain gauge were defined. Receiving many values depending on the load factor from in-flight testing, we could easily compare strain from the in-flight testing with strain from the static strength test. The measurements of strains during the flights were also used as input data for calculation of fatigue life.

Comparisons of the measured strains from in-flight and static strength tests from cut 1 (near the root of the wing) are in Figure 6. From the graph, it can be seen that there is a similar trend in measurement as in the case of 


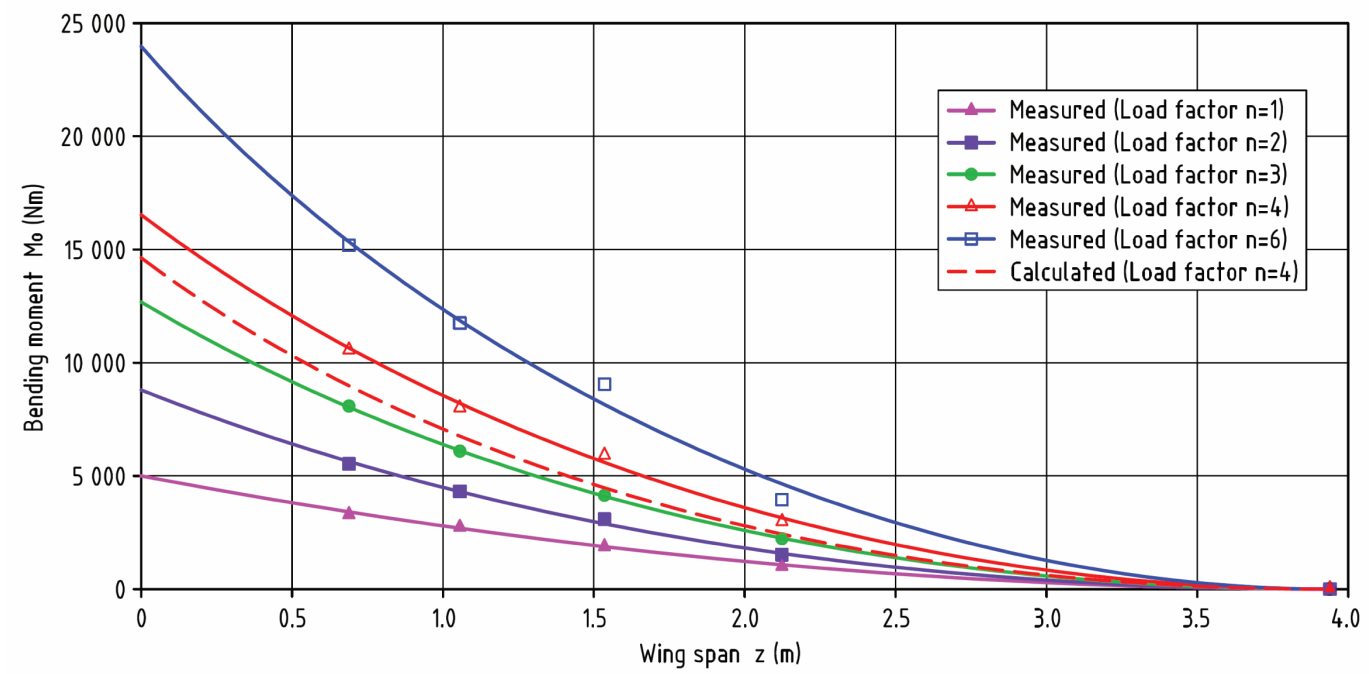

Fig. 5. Comparison of the measured bending moments with calculation

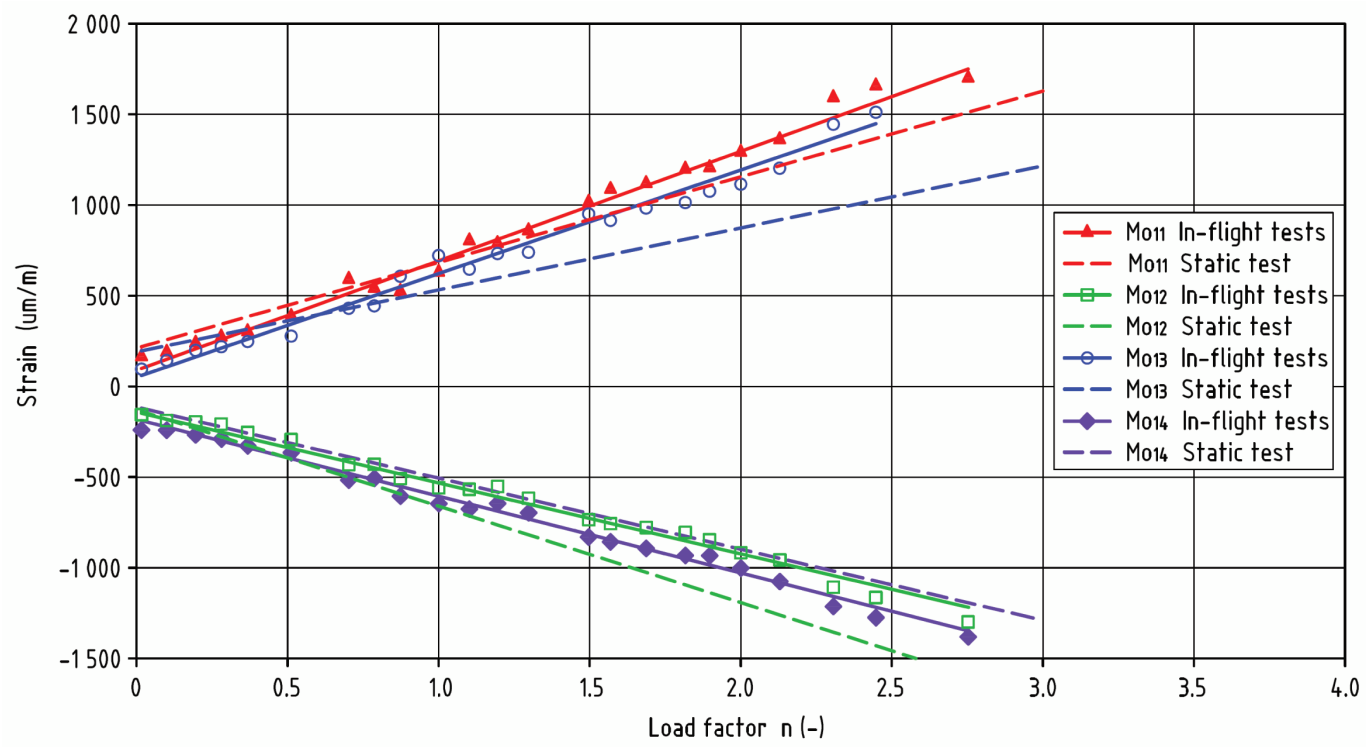

Fig. 6. Comparison of the measured strains from in-flight and static strength tests in cut 1

the bending moment. The strains measured during the flights are a little higher (about fifteen per cent) than the strains measured during the static strength test.

Data from strain gauges used for measurement of the shearing force were analysed too, but it is out of the frame of this article.

\section{Conclusion}

We performed a complete series of tests on a small sport aircraft for purposes of load, strain and fatigue analyses. This way we confirmed the calculation methods used by the aircraft producer and the methodology for measuring bending moments. We also compared strains in defined positions on the spars with the static strength test, thereby indirectly confirming the accuracy of the load calculation. And finally we obtained a valuable data for fatigue calculation.

\section{References}

Jebáček, I. 2005. Load of horizontal tail by manoeuvre, Letecký Zpravodaj (3). ISSN 1211-877X.

Gudkov, A. I.; Lesakov, P. S. 1972. Metody i technika letnykh ispytanij samoletov na prochnost. Moskva (in Russian).

Skopinski, T. H.; Aiken, W. S. 1953. Calibration of strain-gage installation in aircraft structures for the measurement of flight loads, NACA Report (1178). 